\title{
Acid-Base Disorders in Patients with Chronic Obstructive Pulmonary Disease: A Pathophysiological Review
}

\author{
Cosimo Marcello Bruno and Maria Valenti \\ Department of Internal Medicine and Systemic Diseases, University of Catania, 95100 Catania, Italy \\ Correspondence should be addressed to Cosimo Marcello Bruno, cmbruno@unict.it \\ Received 29 September 2011; Accepted 26 October 2011 \\ Academic Editor: Saulius Butenas
}

Copyright () 2012 C. M. Bruno and M. Valenti. This is an open access article distributed under the Creative Commons Attribution License, which permits unrestricted use, distribution, and reproduction in any medium, provided the original work is properly cited.

The authors describe the pathophysiological mechanisms leading to development of acidosis in patients with chronic obstructive pulmonary disease and its deleterious effects on outcome and mortality rate. Renal compensatory adjustments consequent to acidosis are also described in detail with emphasis on differences between acute and chronic respiratory acidosis. Mixed acid-base disturbances due to comorbidity and side effects of some drugs in these patients are also examined, and practical considerations for a correct diagnosis are provided.

\section{Introduction}

Chronic obstructive pulmonary disease (COPD) is a major public health problem. Its prevalence varies according to country, age, and sex. On the basis of epidemiologic data, the projection for 2020 indicates that COPD will be the third leading cause of death worldwide and the fifth leading cause of disability [1]. About 15\% of COPD patients need admission to general hospital or intensive respiratory care unit for acute exacerbation, leading to greater use of medical resources and increased costs [2-5]. Even though the overall prognosis of COPD patients is lately improved, the mortality rate remains high, and, among others, acid-base disorders occurring in these subjects can affect the outcome.

The aim of this paper is to focus on the main pathogenic mechanisms leading to acid-base disorders and their clinical consequences in COPD patients.

\section{Hypercapnia and Respiratory Acidosis}

A major complicance in COPD patients is the development of stable hypercapnia $[6,7]$.

In the healthy subject, about $16,000-20,000 \mathrm{mmol} /$ day of carbon dioxide $\left(\mathrm{CO}_{2}\right)$, derived from oxidation of nutrients containing carbon, are produced. Under normal conditions, the production of $\mathrm{CO}_{2}$ is removed by pulmonary ventilation.
However, an alteration in respiratory exchanges, as occurs in advanced phase of COPD, results in retention of $\mathrm{CO}_{2}$. Carbon dioxide is then hydrated with the formation of carbonic acid that subsequently dissociates with release of hydrogen ions $\left(\mathrm{H}^{+}\right)$in the body fluids according to the following equation:

$$
\mathrm{CO}_{2}+\mathrm{H}_{2} \mathrm{O} \Longrightarrow \mathrm{H}_{2} \mathrm{CO}_{3} \Longrightarrow{ }^{-} \mathrm{HCO}_{3}+\mathrm{H}^{+} .
$$

Thus, the consequence of hypercapnia due to alteration of gas exchange in COPD patients mainly consists in increase of $\mathrm{H}^{+}$concentration and development of respiratory acidosis, also called hypercapnic acidosis [8]. According to the traditional method to assess acid-base status, the HendersonHasselbach equation expresses the relationship between $\mathrm{pH}$ (logarithm of inverse concentration of $\mathrm{H}^{+}$), bicarbonate ion concentration $\left({ }^{-} \mathrm{HCO}_{3}\right)$, and partial pressure of $\mathrm{CO}_{2}$ $\left(\mathrm{pCO}_{2}\right)$ :

$$
\mathrm{pH}=6.1+\log { }^{-} \mathrm{HCO}_{3} / 0.03 \mathrm{pCO}_{2} .
$$

It is evident that the $\mathrm{pH}$ and the concentration of hydrogen ions are strictly determined by the bicarbonate/ $/ \mathrm{PO}_{2}$ ratio, rather than their individual values. A change in $\mathrm{pH}$ can thus be determined by a primitive alteration of numerator of this equation, that is, bicarbonate (metabolic disorders) or of 
denominator, that is, $\mathrm{pCO}_{2}$ (respiratory disorders). In either case, compensatory mechanisms are activated to determine a consensual variation of the other factor to keep this ratio as constant as possible and minimize changes in $\mathrm{pH}$. The extent of these compensatory changes are largely dependent on that of the primary alteration and can be to some extent predicted (expected compensatory response) [9].

Consequently, the compensation to respiratory acidosis consists in a secondary increase in bicarbonate concentration, and the arterial blood gas analysis is characterized by a reduced $\mathrm{pH}$, increased $\mathrm{pCO}_{2}$ (initial variation), and increased bicarbonate levels (compensatory response).

\section{Compensatory Mechanisms in Acute and Chronic Respiratory Acidosis}

The response to respiratory acidosis occurs in a different extent either in acute or chronic phase. When hypercapnia occurs acutely, the buffering of $\mathrm{H}^{+}$takes place by proteins, mainly hemoglobin, and other intracellular nonbicarbonate buffers as follows:

$$
\mathrm{H}_{2} \mathrm{CO}_{3}+{ }^{-} \mathrm{Hb} \Longrightarrow \mathrm{HHb}+{ }^{-} \mathrm{HCO}_{3} .
$$

The effectiveness of this mechanism is limited. In such condition, for every increase of $10 \mathrm{mmHg} \mathrm{pCO}_{2}$ we expect only $1 \mathrm{mEq}$ increase in bicarbonate concentration [10].

Subsequently, renal adaptive changes occur mainly in the proximal tubular cells than in distal tubules leading to increased bicarbonate reabsorption and increased excretion of titratable acid and ammonium $[11,12]$.

$\mathrm{H}^{+}$excretion across apical membrane occurs by a $\mathrm{Na}^{+} / \mathrm{H}^{+}$antiporter (NHE3) and to a lesser extent by a proton pump (Figure 1). The secreted $\mathrm{H}^{+}$into the tubular fluid combines with filtered bicarbonate ions leading to carbonic acid formation. The carbonic anhydrase is then split into $\mathrm{CO}_{2}$ and $\mathrm{H}_{2} \mathrm{O} . \mathrm{CO}_{2}$ diffuses into the cell where $\mathrm{CO}_{2}$ is rehydrated to carbonic acid. This gives rise to bicarbonate ion that exits from the cell through the basolateral membrane into the interstitium via a $3 \mathrm{HCO}_{3} / \mathrm{Na}(\mathrm{NBCe} 1)$ symporter, while $\mathrm{H}^{+}$ is secreted again into the lumen. The basolateral membrane $\mathrm{Na}^{+} / \mathrm{K}^{+}$ATPase antiporter, maintaining a low intracellular sodium concentration, further enhances the NHE3 activity.

In summary, reabsorption of bicarbonate requires carbonic anhydrase and is strictly associated to natrium reabsorption.

Experimental studies show that total NHE3 and NBCe1 protein abundance are upregulated by chronic respiratory acidosis [13]. However, the main mechanism responsible for the elevation in serum bicarbonate is the increased excretion of titratable acid and ammonium [12], which are stimulated by persistently elevated $\mathrm{pCO}_{2}$.

Ammonia $\left(\mathrm{NH}_{3}\right)$, in the proximal cell, is formed by deamination of glutamine to glutamic acid and then to alpha-ketoglutarate. Therefore, for each molecule of glutamine, two molecules of ammonia are formed (Figure 2). Ammonia binds $\mathrm{H}^{+}$resulting in ammonium ion $\left(\mathrm{NH}_{4}{ }^{+}\right)$ which is subsequently secreted into the renal tubular lumen by NHE3, with $\mathrm{NH}_{4}{ }^{+}$substituting for $\mathrm{H}^{+}$on the transporter, and excreted into the urine as ammonium chloride $\left(\mathrm{NH}_{4} \mathrm{Cl}\right)$. For alternative, some $\mathrm{NH}_{4}{ }^{+}$can be secreted into the tubular fluid as $\mathrm{NH}_{3}$, where it is then protonated. Thus, ammonia replaces bicarbonate ion acting as urinary buffer and binding hydrogen ion. Consequently, for each $\mathrm{H}^{+}$excreted as ammonium ion, a "new ${ }^{-} \mathrm{HCO}_{3}$ " is returned to the blood. Nevertheless, a significant reabsorption of $\mathrm{NH}_{4}{ }^{+}$occurs in the ascending limb of the loop of Henle. In the distal tubule, $\mathrm{NH}_{4}{ }^{+}$reabsorbed is subsequently excreted by a $\mathrm{NH}_{4}{ }^{+}$-transporter belonging to $\mathrm{Rh}$ glycoproteins family, localized on both apical and basolateral membranes of collecting duct cells [14].

Thus, collecting duct cells plays a pivotal role in maintaining acid-base balance and net acid excretion. If ammonium reabsorbed was not excreted in the urine, it would be metabolized by the liver generating $\mathrm{H}^{+}$, and a "new ${ }^{-} \mathrm{HCO}_{3}$ " production would be negated.

Inorganic phosphates, particularly in the distal nephron, also play a role.

$\mathrm{H}^{+}$derived from the breakdown of carbonic acid are excreted into the tubular lumen where they are buffered by phosphates $\left({ }^{2-} \mathrm{HPO}_{4}+\mathrm{H}^{+} \Rightarrow{ }^{-} \mathrm{H}_{2} \mathrm{PO}_{4}\right)$, while ${ }^{-} \mathrm{HCO}_{3}$ crosses the basolateral membrane via an anion exchange (AE) $\mathrm{Cl}^{-} /{ }^{-} \mathrm{HCO}_{3}$ antiporter (Figure 3).

Phosphates then bind hydrogen ions replacing "regenerated" bicarbonate ions. Interestingly, acidemia and hypercapnia reduce the threshold for reabsorption of phosphate, thus making available a larger amount of urinary buffer in the distal tubule $[15,16]$.

Pendrin is a bicarbonate/chloride exchanger located in the apical domain of the type $\mathrm{B}$ and non- $\mathrm{A}$, non-B intercalated cell of collecting ducts (Figure 4). Hypercapnia determines a reduction of pendrin expression by up to $50 \%$, contributing to the increased plasma bicarbonate and decreased plasma chloride observed in chronic respiratory acidosis $[11,17]$.

The renal response is completed in its full extent after 35 days, resulting in a new steady state in which increase of $3.5 \mathrm{mEq}$ in bicarbonate concentration is expected for every increase of $10 \mathrm{mmHg} \mathrm{pCO}_{2}[18,19]$. Then, in the setting of chronic respiratory acidosis, renal compensation offers more significant $\mathrm{pH}$ protection in contrast to intracellular buffering in the acute situation.

For example, if we consider an acute $\mathrm{pCO}_{2}$ increase to $80 \mathrm{mmHg}$, bicarbonate concentration compensatory increases by $4 \mathrm{mEq}$.

In agreement to Henderson-Hasselbach equation,

$$
\mathrm{pH}=6.1+\log (28 / 0.03 \times 80)=7.17 .
$$

Conversely, if we consider a chronic increase of $\mathrm{pCO}_{2}$ to $80 \mathrm{mmHg}$, we could observe a compensatory increase of about $14 \mathrm{mEq}$ in bicarbonate concentration. Thus,

$$
\mathrm{pH}=6.1+\log (38 / 0.03 \times 80)=7.29 .
$$

In the last example, the variation in $\mathrm{pH}$ value is significantly smaller than in the previous one $(0.11$ versus 0.23 units). This explains why chronic respiratory acidosis is generally less severe and better tolerated than acute with similar 


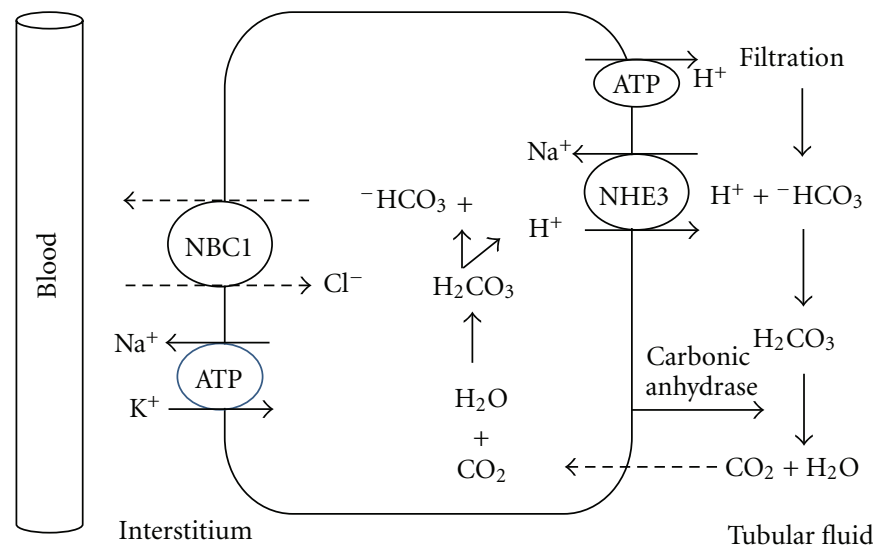

FIgURE 1: $\mathrm{H}^{+}$secretion and ${ }^{-} \mathrm{HCO}_{3}$ reabsorption in the tubular cells.
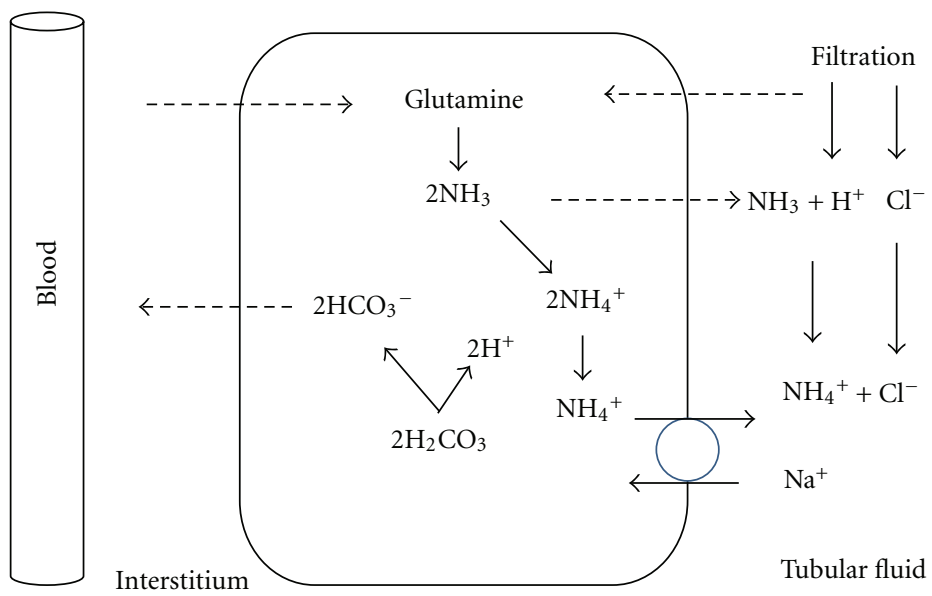

FIGURE 2: Cellular mechanism for ammoniagenesis and $\mathrm{NH}_{4}{ }^{+}$secretion. $\mathrm{NH}_{3}$ can be secreted into the tubular fluid, where it is then protoned, or it can bind $\mathrm{H}^{+}$within the cell, and be secreted as ammonium ion.

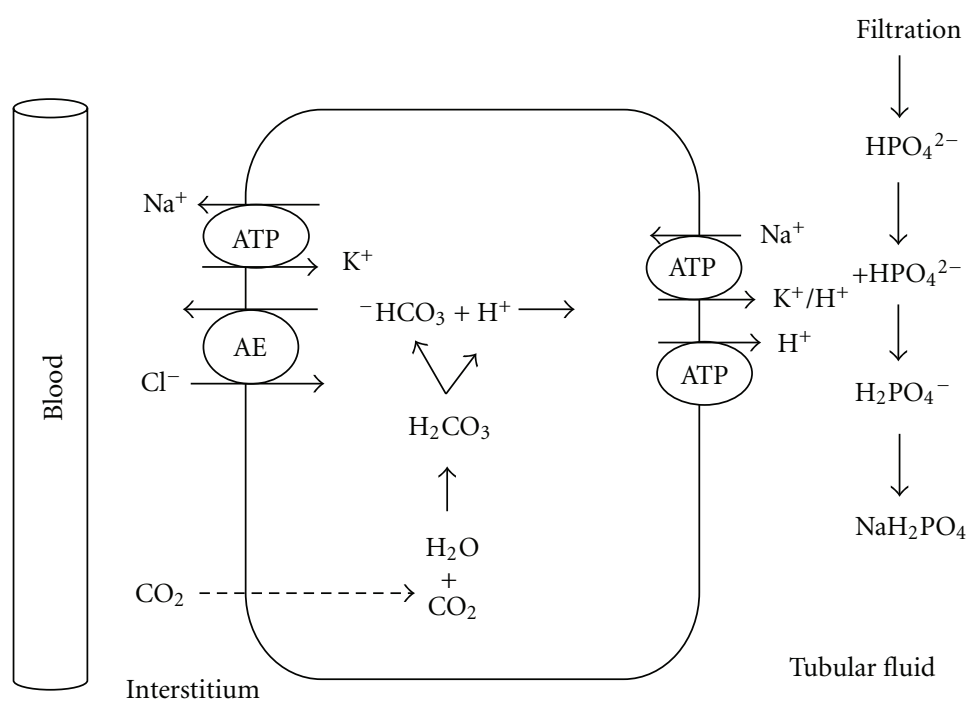

FIGURE 3: Titration of nonvolatile acids. $\mathrm{H}^{+}$secreted into the tubular fluid combines with phosphate (urinary buffer), and a new ${ }^{-} \mathrm{HCO}_{3}$ is generated within the cell. 


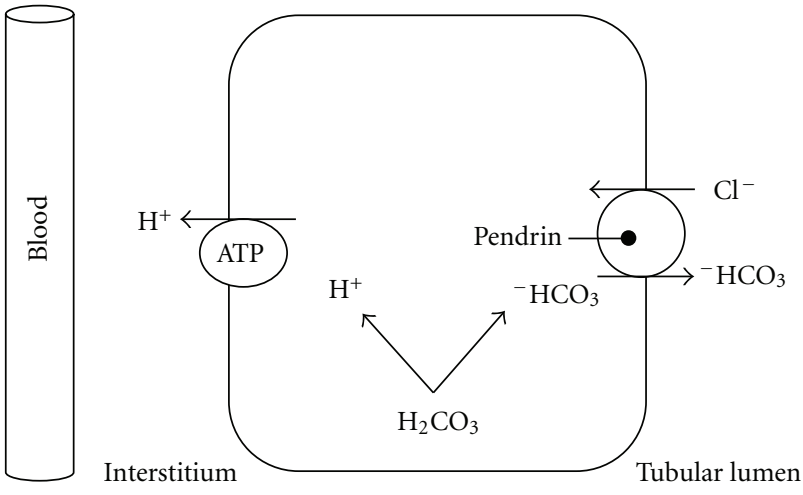

Figure 4: Pendrin, localized in the cellular apical membrane of cortical collecting ducts and connecting tubules, acts as a $\mathrm{Cl}^{-} /{ }^{-} \mathrm{HCO}_{3}$ exchanger regulating the acid-base status and chloride homeostasis.

hypercapnia. Figure 5 shows the different slope of the relationship between $\mathrm{pCO}_{2}$ and bicarbonate in acute and chronic respiratory acidosis.

\section{Clinical Consequences of Acidosis}

Acidosis is an adverse prognostic indicator and is responsible for several deleterious effects on hemodynamics and metabolism [20-22]. Acidosis causes myocardial depression, arrhythmias, decrease of peripheral vascular resistances, and hypotension. In addition, hypercapnic acidosis is responsible for weakness of respiratory muscles, increase of proinflammatory cytokines and apoptosis, and cachexia. Moreover, in hypercapnic COPD patients a decrease of renal blood flow, an activation of the renin-angiotensin system, and increase of circulating values of antidiuretic hormone, atrial natriuretic peptide, and endothelin-1 have been reported [23]. It has been supposed that these hormonal abnormalities can play a role in retention of salt and water and development of pulmonary hypertension, independently from the presence of myocardial dysfunction.

Clinical and epidemiological data clearly demonstrate that severity of acidosis is associate with poor prognosis.

In the study of 139 patients with COPD and respiratory failure, Jeffrey et al. [24] concluded that arterial $\mathrm{H}^{+}$concentration is an important prognostic factor for survival.

In a retrospective study on 295 episodes of COPD exacerbation, Guy et al. [25] reported that intubation and mortality rate was highest at the lowest $\mathrm{pH}$ group. Similarly, Kettel et al. [26] and Warren et al. [27] reported an higher mortality rate in patients with a $\mathrm{pH}$ value at admission below 7.23 and 7.26, respectively. Plant et al. [28] reported that the more acidemic patients had an higher mortality rate both in group with conventional therapy and in group undergone to noninvasive ventilation. Similar findings were reported by more recent papers [29-31] confirming that a more severe acidosis worsens the outcome of COPD patients.

Prognosis of COPD patients is also adversely affected by comorbidity. Chronic renal failure was found associated with COPD in $22-44 \%$ of cases, depending on the study series

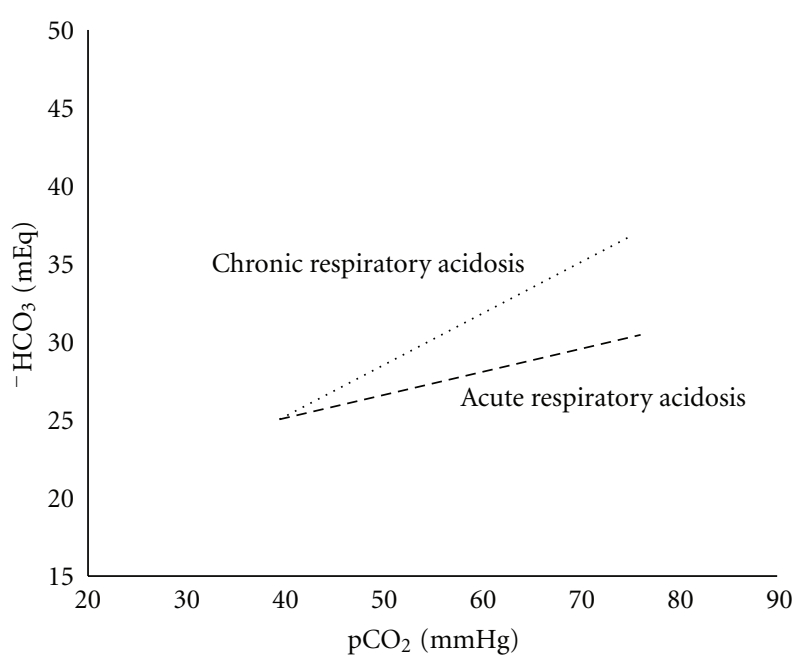

FIGURE 5: Relationship between $\mathrm{pCO}_{2}$ and bicarbonate in acute and chronic respiratory acidosis.

and diagnostic criteria [32-34]. Renal failure can contribute to development of hypertension, peripheral arterial vascular disease, and onset of ischemic heart disease.

In addition, when renal failure occurs in COPD patients, the compensatory role of kidney in respiratory acidosis may be less effective, resulting in a reduced ammoniagenesis and titratable acidity production with consequent smaller increase of serum bicarbonate and more severe acidosis. Clinical reports demonstrated that bicarbonate levels in these patients are inversely related to survival and that concomitant renal failure is predictive of death and risk of exacerbation $[31,35,36]$.

These previous clinical studies indirectly confirm the role and the importance of kidney function as compensatory organ in acid-base disorders.

\section{Mixed Acid-Base Disorders}

Respiratory acidosis is not the only acid-base disturbance observed in patients with COPD. The presence of comorbidity and side effects of some drugs used to treat COPD patients cause different disorders. These conditions are defined as mixed acid-base disorders.

The main clinical conditions leading to a mixed acidbase disorder are summarized in Table 1. Heart failure, acute pulmonary edema, renal failure, and the onset of sepsis or severe hypoxia are, for example, the most common causes of metabolic acidosis associated with hypercapnia. An abuse of diuretics with volume depletion, hypokalaemia, and use of steroids are the most commonly associated factors with simultaneous presence of metabolic alkalosis.

Metabolic alkalosis may also be the consequence of a too rapid removal of $\mathrm{CO}_{2}$ in patients undergoing mechanical ventilation. In these subjects, the kidney is not able to quickly remove the bicarbonate excess after the normalization of $\mathrm{CO}_{2}$ tension, even though some authors hypothesized that cellular transport processes might have a "memory" of preexisting conditions, and increased bicarbonate reabsorption might persist for some time $[13,37]$. 
TABLE 1: Mixed acid-base disturbances in COPD.

\begin{tabular}{ll}
\hline Acute on chronic respiratory acidosis & Respiratory acidosis and metabolic alkalosis \\
\hline & Volume depletion \\
& Diuretics \\
Reexacerbation of COPD & Vomiting \\
& Severe hypokalemia \\
& Steroids \\
\hline Respiratory acidosis and metabolic acidosis & Posthypercapnic alkalosis \\
\hline Severe hypoxemia & Resp. acidosis, met. acidosis, and met. alkalosis \\
Acute pulmonary edema & \\
Renal failure & \\
Sepsis & \\
Shock & Renal failure and vomiting \\
Diabetes mellitus & Severe hypoxemia and volume depletion \\
Acute alcoholism & Sepsis and hypokalemia \\
Exogenous poisoning & \\
\hline
\end{tabular}

Both metabolic acidosis and metabolic alkalosis can coexist with respiratory acidosis. This clinical setting may occur, for example, in patients with COPD who develop heart failure and are treated with high doses of diuretics or who have renal failure and vomiting or severe hypoxia and extracellular volume depletion.

In these cases, even if the final shift of the $\mathrm{pH}$ depends on the prevalence of acidogenic or alkalogenic factors, the production and/or removal of both metabolic bases and inorganic acids are altered.

Systematically investigated studies on acid-base disorders in patients with COPD are few, but there are evidences that about one-third of these patients have multiple disorders in which the associated respiratory acidosis-metabolic alkalosis is the most frequently found disorder [38, 39].

The presence of a mixed acid-base disturbance complicates the clinical pathophysiology and poses difficulties in diagnosis and treatment.

A limitation of the Henderson-Hasselbach method in this clinical setting is the dependence of serum bicarbonate on $\mathrm{pCO}_{2}$. A variation in the bicarbonate level can be due to a metabolic disorder or can be the consequence of an initial variation in $\mathrm{pCO}_{2}$. In the mixed disorders, the bicarbonate level can result in a confounding factor because the altered bicarbonate value, alone, suggests an acid-base imbalance, but it does not distinguish the metabolic component from respiratory component.

Therefore, alternative methods have been proposed to better quantify the metabolic component in mixed disorders.

Among these, standard base excess (SBE), corrected anion gap (cAG), and the Stewart approach are the most frequently utilized [40-43].

SBE can be defined as the amount of strong acid or strong base that must be added to each liter of fully oxygenated blood to restore the $\mathrm{pH}$ to 7.40 at a temperature of $37^{\circ} \mathrm{C}$ and $\mathrm{pCO}_{2}$ kept at $40 \mathrm{mmHg}$ and hemoglobin concentration standardized to $5 \mathrm{~g} / \mathrm{dL}$. The cAG is the difference between the sum of the main cations and the main anions, corrected for albumin concentration and serum phosphate. Nevertheless, SBE and cAG do not entirely solve the problem and are been criticized.

SBE is an approach that extrapolates results "in vitro" to the more complex multicompartimental real-life situation of body fluids because, in vivo, acid or base loads are not only titrated in the blood compartment, and total buffering capacity can be different from in vitro.

Furthermore, SBE does not resolve the interdependence of $\mathrm{pCO}_{2}$ and bicarbonate because, in respiratory disorders, the renal compensatory adjustments result in changes in SBE.

The cAG should reveal the presence of unmeasured anions in the blood, and it is useful to determine the cause of metabolic acidosis (hyperchloremic rather than normochloremic) once it has been diagnosed.

The Stewart approach [43] is based on the principals of conservation of mass, electrical neutrality, and dissociation constant of electrolytes and identified three independent variables determining hydrogen ion concentration in solution: strong ion difference (SID), $\mathrm{pCO}_{2}$, and total weak acid $\left(\mathrm{A}_{\text {tot }}\right)$. Although Stewart method proposes a different approach, its reliability compared to the traditional method is still a debated question. Some authors $[39,44,45]$ consider the diagnostic performance of the Stewart method better than the conventional approach to assess acid-base status, especially to quantify the metabolic component, but others [46-49] concluded that it does not improve the diagnostic accuracy and does not provide any tool to better manage these disorders because the traditional approach, with only minor adjustments, can provide the same practical information.

So when and how to suspect a mixed disorder according to the traditional method?

For this purpose, a stepwise approach has been proposed by several authors [50-53], and some simple concepts could help in supposing the presence of a mixed disorder.

(1) Discordant Variation of Bicarbonates and $\mathrm{pCO}_{2}$. Compensatory mechanisms are aimed to keep constant 
bicarbonate $/ \mathrm{pCO}_{2}$ ratio, and a primitive variation of one of the terms is followed by a consensual variation of the other. Therefore, increase of bicarbonates and decrease of $\mathrm{pCO}_{2}$ or decrease of bicarbonates and increase of $\mathrm{pCO}_{2}$ suggest a mixed disorder.

(2) The Presence of Normal $p H$ Value and Significant Alteration in Bicarbonates and $\mathrm{pCO}_{2}$ Levels Also Suggest a Mixed Disorder. The adaptive mechanisms do not restore the $\mathrm{pH}$ to a normal value. Normal $\mathrm{pH}$, in this case, argues for the coexistence of two opposing problems rather than a perfectly compensated simple disorder.

(3) Compensatory Response Is Significantly Different than Expected Response. Observed bicarbonate levels or $\mathrm{pCO}_{2}$ significantly different than "expected" proves the existence of a mixed disorder. In fact, the amount of compensatory variation depends on the extension of primitive change, and it can be reasonably provided. When expected response does not occur, there is an additive disorder responsible for variation of bicarbonate or $\mathrm{pCO}_{2}$.

(4) Delta Ratio, That Is, $\Delta a n i o n$ gap $/ \triangle \mathrm{HCO}_{3}>2$. When a metabolic acid (HA) is added to extracellular fluid, it dissociates in $\mathrm{H}^{+}$and organic anion $\left({ }^{-} \mathrm{A}\right) . \mathrm{H}^{+}$react with a molecule of bicarbonate while unmeasured organic anion $\left({ }^{-} \mathrm{A}\right)$ will increase anion gap (positive less negative charges). Theoretically, the variation in the anion gap should be equal to the decrease in bicarbonate so that the ratio between these two changes should be equal to one. Nevertheless, a significant amount of organic acid is buffered by intracellular proteins, not by ${ }^{-} \mathrm{HCO}_{3}$, while most of excess anions remain in the extracellular fluids because they do not freely cross the cellular membrane. Consequently, in a pure metabolic acidosis, the change in bicarbonate concentration is lesser than anion gap, and delta ratio is between 1 and 2. A delta ratio value above 2 indicates a lesser fall in bicarbonate than expected on basis of the change in anion gap. This finding suggests a concurrent metabolic alkalosis or preexisting high $\mathrm{HCO}_{3}$ levels due to chronic respiratory acidosis.

In any case, the interpretation of arterial blood gas analysis cannot ignore the findings of clinical history and physical examination that can support a correct diagnosis.

Clinicians should also consider the preexisting conditions, drugs usually taken, symptoms presented in the last days and hours as well as hydration status of patients, the presence of heart and renal failure, diabetes, hypokalemia, or signs of sepsis.

Therapy of mixed disorders is often difficult. The attempt to correct the $\mathrm{pH}$ at all costs with the use of alkaline or acidifying drugs could be harmful, and the clinician's attention should be paid to identify underlying pathophysiological changes.

\section{Conclusions}

Respiratory acidosis due to hypercapnia is a common and severe complication observed in patients with chronic obstructive pulmonary disease in advanced phase. Development of acidosis worsens the prognosis and is associated with higher mortality rate. Mechanisms of compensation consist of an increased renal reabsorption of bicarbonate and increased excretion of $\mathrm{H}^{+}$. These adjustments of renal function are more effective in chronic form and explain why the latter is less severe and better tolerated than acute. Mixed acid-base disorders are also frequently observed in COPD patients. Clinical history, physical examination, and a careful evaluation of arterial blood gas analysis may help in proper diagnosis and targeted therapy.

\section{References}

[1] C. Raherison and P. O. Girodet, "Epidemiology of COPD," European Respiratory Review, vol. 18, no. 114, pp. 213-221, 2009.

[2] D. C. McCrory, C. Brown, S. E. Gelfand, and P. B. Bach, "Management of acute exacerbations of COPD: a summary and appraisal of published evidence," Chest, vol. 119, no. 4, pp. 1190-1209, 2001.

[3] P. K. Plant and M. W. Elliott, "Chronic obstructive pulmonary disease: management of ventilatory failure in COPD," Thorax, vol. 58, no. 6, pp. 537-542, 2003.

[4] P. K. Plant, J. L. Owen, and M. W. Elliott, "One year period prevalence study of respiratory acidosis in acute exacerbations of COPD: implications for the provision of non-invasive ventilation and oxygen administration," Thorax, vol. 55, no. 7, pp. 550-554, 2000.

[5] G. L. Schumaker and S. K. Epstein, "Managing acute respiratory failure during exacerbation of chronic obstructive pulmonary disease," Respiratory Care, vol. 49, no. 7, pp. 766$782,2004$.

[6] M. G. Seneff, D. P. Wagner, R. P. Wagner, J. E. Zimmerman, and W. A. Knaus, "Hospital and 1-year survival of patients admitted to intensive care units with acute exacerbation of chronic obstructive pulmonary disease," Journal of the American Medical Association, vol. 274, no. 23, pp. 1852-1857, 1995.

[7] D. A. Kregenow, G. D. Rubenfeld, L. D. Hudson, and E. R. Swenson, "Hypercapnic acidosis and mortality in acute lung injury," Critical Care Medicine, vol. 34, no. 1, pp. 1-7, 2006.

[8] N. Madias and J. Cohen, "Respiratory acidosis," in Acid Base, J. Kassirer and J. Cohen, Eds., pp. 307-348, Little Brown, Boston, Mass, USA, 1982.

[9] B. D. Rose, "Introduction to simple and mixed acid-base disorders," in Clinical Physiology of Acid-base and Electrolyte Disorders, pp. 429-441, McGraw-Hill, New York, NY, USA, 1994.

[10] N. C. Brackett Jr., J. J. Cohen, and W. B. Schwartz, "Carbon dioxide titration curve of normal man; effect of increasing degrees of acute hypercapnia on acid-base equilibrium," The New England journal of medicine, vol. 272, pp. 6-12, 1965.

[11] S. de Signeux, H. Malte, H. Dimke, J. Frokiaer, S. Nielsen, and S. Frische, "Renal compensation to chronic hypoxic hypercapnia: downregulation of pendrin and adaption of the proximal tubule," American Journal of Physiology: Renal Physiology, vol. 292, pp. F1256-F1266, 2007.

[12] B. M. Koeppen, "The kidney and acid-base regulation," American Journal of Physiology: Advances in Physiology Education, vol. 33, no. 4, pp. 275-281, 2009.

[13] M. G. Cogan, "Chronic hypercapnia stimulates proximal bicarbonate reabsorption in the rat," Journal of Clinical Investigation, vol. 74, no. 6, pp. 1942-1947, 1984.

[14] B. M. Koeppen and B. A. Stanton, Berne and Levy Physiology, Mosby, St. Louis, Mo, USA, 6th edition, 2008.

[15] J. Guntupalli, B. Eby, and K. Lau, "Mechanism for the phosphaturia of NH4Cl: dependence on acidemia but not on diet $\mathrm{PO}_{4}$ or PTH," The American journal of physiology, vol. 242, no. 5, pp. F552-F600, 1982. 
[16] J. Guntupalli, B. Matthews, B. Carlin, and E. Bourke, "Effect of acute hypercapnia on PTH-stimulated phosphaturia in dietary Pi-deprived rat," American Journal of Physiology, vol. 253, no. 1, pp. F34-F40, 1987.

[17] C. A. Wagner, K. E. Finberg, P. A. Stehberger et al., "Regulation of the expression of the CL-/anion exchanger pendrin in mouse kidney by acid-base status," Kidney International, vol. 62, no. 6, pp. 2109-2117, 2002.

[18] N. Madias and H. Adrogue, "Respiratory acidosis and alkalosis," in Respiratory Monitoring (Contemporary Management in Critical Care), M. Tobin, Ed., vol. I, no. 4, pp. 17-53, Churchill Livingstone, Edimburgh, UK, 1991.

[19] S. K. Epstein and N. Singh, "Respiratory acidosis," Respiratory Care, vol. 46, no. 4, pp. 366-383, 2001.

[20] G. G. Nahas, "The problems of acidosis," Journal of Clinical Pathology, vol. 23, supplement 4, pp. 73-83, 1970.

[21] J. M. Handy and N. Soni, "Physiological effects of hyperchloraemia and acidosis," British Journal of Anaesthesia, vol. 101, no. 2, pp. 141-150, 2008.

[22] J. A. Kraut and N. E. Madias, "Metabolic acidosis: pathophysiology, diagnosis and management," Nature Reviews Nephrology, vol. 6, no. 5, pp. 274-285, 2010.

[23] I. S. Anand, Y. Chandrashekhar, R. Ferrari et al., "Pathogenesis of congestive state in chronic obstructive pulmonary disease: studies of body water and sodium, renal function, hemodynamics, and plasma hormones during edema and after recovery," Circulation, vol. 86, no. 1, pp. 12-21, 1992.

[24] A. A. Jeffrey, P. M. Warren, and D. C. Flenley, "Acute hypercapnic respiratory failure in patients with chronic obstructive lung disease: risk factors and use of guidelines for management," Thorax, vol. 47, no. 1, pp. 34-40, 1992.

[25] W. S. H. Guy, N. Hakimian, and S. M. Santiago, "Hypercapnic respiratory failure in COPD patients. Response to therapy," Chest, vol. 117, no. 1, pp. 169-177, 2000.

[26] L. J. Kettel, C. F. Diener, J. O. Morse, H. F. Stein, and B. Burrows, "Treatment of acute respiratory acidosis in chronic obstructive lung disease," Journal of the American Medical Association, vol. 217, no. 11, pp. 1503-1508, 1971.

[27] P. M. Warren, D. C. Flenley, J. S. Millar, and A. Avery, "Respiratory failure revisited: acute exacerbations of chronic bronchitis between 1961-68 and 1970-76," Lancet, vol. 1, no. 8166, pp. 467-470, 1980.

[28] P. K. Plant, J. L. Owen, and M. W. Elliott, "Early use of noninvasive ventilation for acute exacerbations of chronic obstructive pulmonary disease on general respiratory wards: a multicentre randomised controlled trial," Lancet, vol. 355, no. 9219, pp. 1931-1935, 2000.

[29] B. O. Onadekoa, M. Khadadaha, N. Abdellaa et al., "Prognostic factors in the management of exacerbation of chronic obstructive pulmonary disease in Kuwait," Medical Principles and Practice, vol. 14, no. 1, pp. 35-40, 2005.

[30] S. Budweiser, R. A. Jörres, T. Riedl et al., "Predictors of survival in COPD patients with chronic hypercapnic respiratory failure receiving noninvasive home ventilation," Chest, vol. 131, no. 6 , pp. 1650-1658, 2007.

[31] I. Ucgun, F. Oztuna, C. E. Dagli, H. Yildirim, and C. Bal, "Relationship of metabolic alkalosis, azotemia and morbidity in patients with chronic obstructive pulmonary disease and hypercapnia," Respiration, vol. 76, no. 3, pp. 270-274, 2008.

[32] R. Antonelli Incalzi, A. Corsonello, C. Pedone, S. Battaglia, G. Paglino, and V. Bellia, "Chronic renal failure: a neglected comorbidity of COPD,” Chest, vol. 137, pp. 831-837, 2010.

[33] Y. R. van Gestel, M. Chonchol, S. E. Hoeks et al., "Association between chronic obstructive pulmonary disease and chronic kidney disease in vascular surgery patients," Nephrology Dialysis Transplantation, vol. 24, no. 9, pp. 2763-2767, 2009.

[34] C. Terzano, V. Conti, F. di Stefano et al., "Comorbidity, hospitalization, and mortality in COPD: results from a longitudinal study," Lung, vol. 188, no. 4, pp. 321-329, 2010.

[35] G. C. Khilnani, A. Banga, and S. K. Sharma, "Predictors of mortality of patients with acute respiratory failure secondary to chronic obstructive pulmonary disease admitted to an intensive care unit: a one year study," BMC Pulmonary Medicine, vol. 4, article 12, 2004.

[36] A. Banga and G. C. Khilnani, "A comparative study of characteristics and outcome of patients with acute respiratory failure and acute on chronic respiratory failure requiring mechanical ventilation," Indian Journal of Critical Care Medicine, vol. 10, no. 2, pp. 80-87, 2006.

[37] C. van Ypersele de Strihou, P. F. Gulyassy, and W. B. Schwartz, "Effects of chronic hypercapnia on electrolyte and acid-base equilibrium. III. Characteristics of the adaptive and recovery process as evaluated by provision of alkali," Journal of Clinical Investigation, vol. 41, pp. 2246-2253, 1962.

[38] V. Saini, N. Saini, J. Kaur, and G. P. Singh, "Acid base status in chronic obstructive pulmonary disease patients," Indian Journal of Clinical Biochemistry, vol. 8, no. 1, pp. 36-38, 1993.

[39] C. Guérin, P. Nesme, V. Leray et al., "Quantitative analysis of acid-base disorders in patients with chronic respiratory failure in stable or unstable respiratory condition," Respiratory Care, vol. 55, no. 11, pp. 1453-1463, 2010.

[40] O. Siggard-Andersen, The Acid-Base Status of the Blood, Munksgaard Publishers, Copenhagen, Denmark, 1974.

[41] R. Schlichtig, A. W. Grogono, and J. W. Severinghaus, "Human $\mathrm{Pa}_{\mathrm{CO} 2}$ and standard base excess compensation for acid-base imbalance," Critical Care Medicine, vol. 26, no. 7, pp. 11731179, 1998.

[42] M. Emmett and R. G. Narins, "Clinical use of the anion gap," Medicine, vol. 56, no. 1, pp. 38-54, 1977.

[43] P. A. Stewart, "Modern quantitative acid-base chemistry," Canadian Journal of Physiology and Pharmacology, vol. 61, no. 12, pp. 1444-1461, 1983.

[44] V. Fencl, A. Jabor, A. Kazda, and J. Figge, "Diagnosis of metabolic acid-base disturbances in critically III patients," American Journal of Respiratory and Critical Care Medicine, vol. 162, no. 6, pp. 2246-2251, 2000.

[45] M. M. Boniatti, P. R. C. Cardoso, R. K. Castilho, and S. R. R. Vieira, "Acid-base disorders evaluation in critically ill patients: we can improve our diagnostic ability," Intensive Care Medicine, vol. 35, no. 8, pp. 1377-1382, 2009.

[46] M. Moviat, F. van Haren, and H. van der Hoeven, "Conventional or physicochemical approach in intensive care unit patients with metabolic acidosis," Critical Care, vol. 7, no. 3, pp. R41-R45, 2003.

[47] A. A. Sirker, A. Rhodes, R. M. Grounds, and E. D. Bennett, "Acid-base physiology: the traditional and the modern approaches," Anaesthesia, vol. 57, no. 4, pp. 348-356, 2002.

[48] I. Kurtz, J. Kraut, V. Ornekian, and M. K. Nguyen, "Acid-base analysis: a critique of the Stewart and bicarbonate-centered approaches," American Journal of Physiology: Renal Physiology, vol. 294, no. 5, pp. F1009-F1031, 2008.

[49] A. Rastegar, "Clinical utility of Stewart's method in diagnosis and management of acid-base disorders," Clinical Journal of the American Society of Nephrology, vol. 4, no. 7, pp. 1267$1274,2009$.

[50] R. G. Narins and M. Emmett, "Simple and mixed acid-base disorders: a practical approach," Medicine, vol. 59, no. 3, pp. 161-187, 1980. 
[51] T. D. DuBose Jr., "Clinical approach to patients with acid-base disorders," Medical Clinics of North America, vol. 67, no. 4, pp. 799-813, 1983.

[52] P. J. Fall, "A stepwise approach to acid-base disorders. Practical patient evaluation for metabolic acidosis and other conditions," Postgraduate Medicine, vol. 107, no. 3, pp. 249263, 2000.

[53] P. Sood, G. Paul, and S. Puri, "Interpretation of arterial blood gas," Indian Journal of Critical Care Medicine, vol. 14, no. 2, pp. 57-64, 2010. 


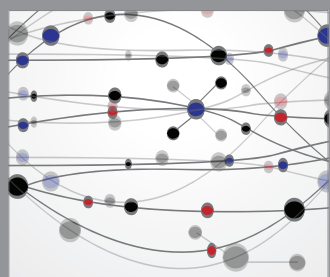

The Scientific World Journal
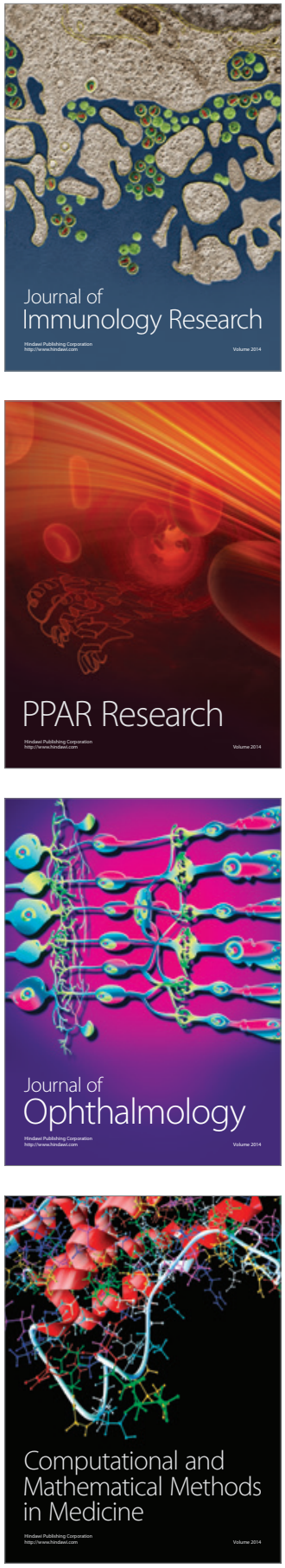

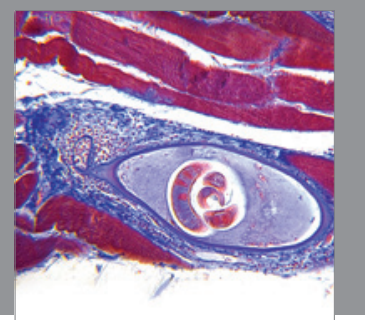

Gastroenterology

Research and Practice
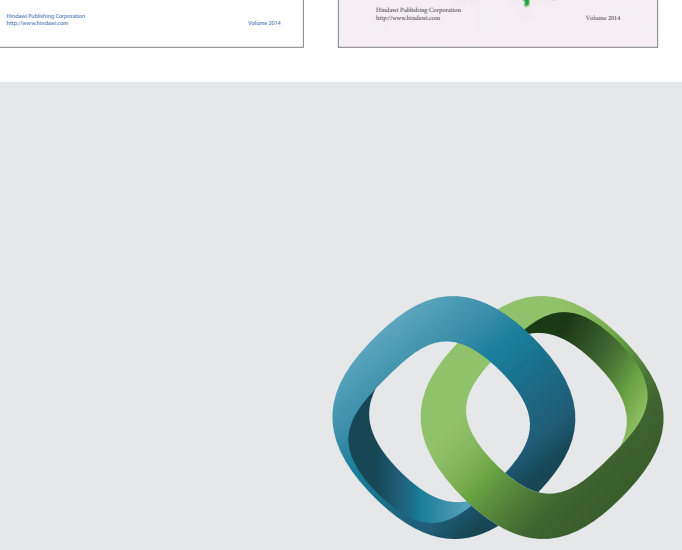

\section{Hindawi}

Submit your manuscripts at

http://www.hindawi.com
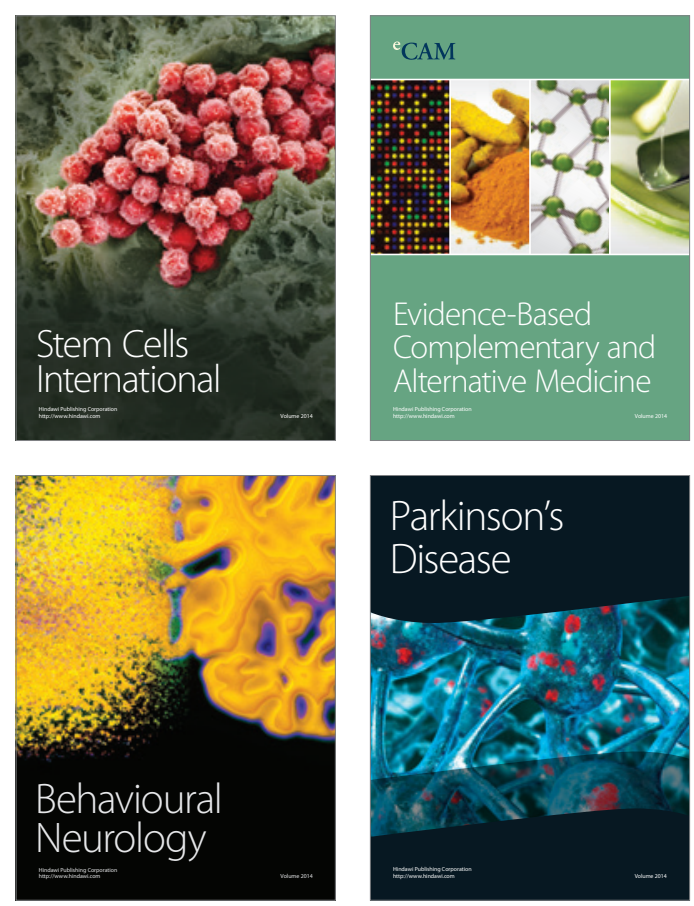

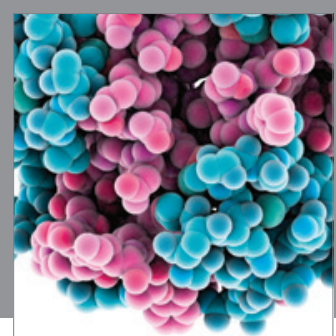

Journal of
Diabetes Research

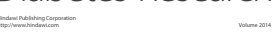

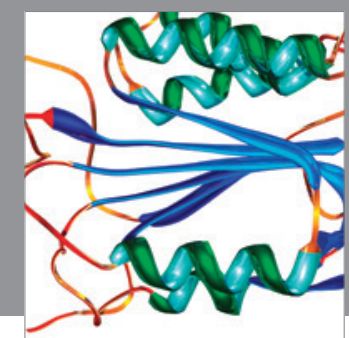

Disease Markers
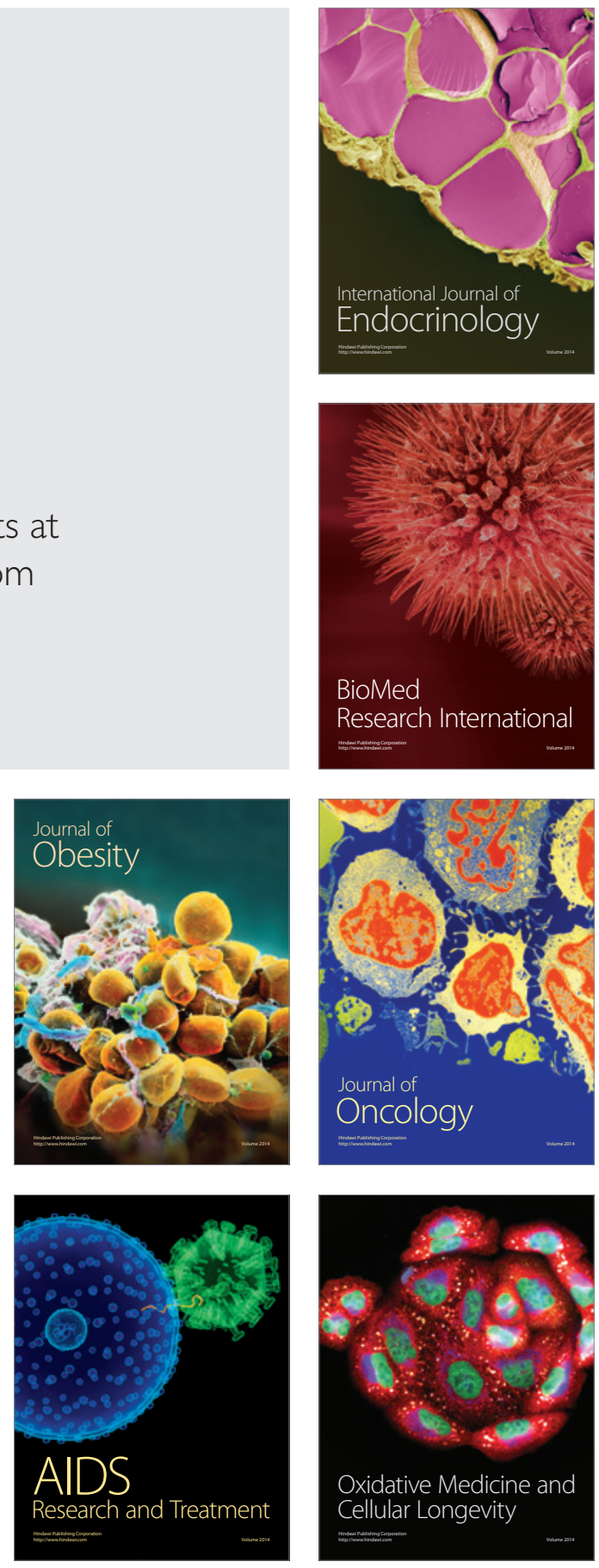